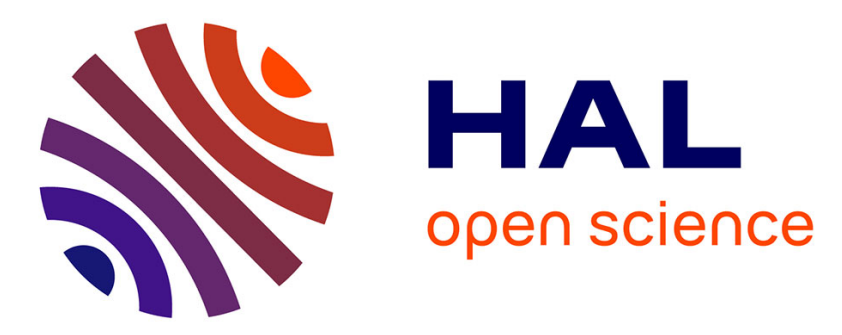

\title{
Feedback Control of the Spray Liquid Distribution of Electrostatically assisted Coaxial atomization
}

\author{
Rodrigo Osuna-Orozco, Nathanaël Machicoane, Peter D Huck, Alberto
}

Aliseda

\section{- To cite this version:}

Rodrigo Osuna-Orozco, Nathanaël Machicoane, Peter D Huck, Alberto Aliseda. Feedback Control of the Spray Liquid Distribution of Electrostatically assisted Coaxial atomization. Atomization and Sprays, 2020, 30 (1), pp.1-9. 10.1615/AtomizSpr.2020033430 . hal-02944235

\section{HAL Id: hal-02944235 \\ https://hal.science/hal-02944235}

Submitted on 27 Sep 2020

HAL is a multi-disciplinary open access archive for the deposit and dissemination of scientific research documents, whether they are published or not. The documents may come from teaching and research institutions in France or abroad, or from public or private research centers.
L'archive ouverte pluridisciplinaire HAL, est destinée au dépôt et à la diffusion de documents scientifiques de niveau recherche, publiés ou non, émanant des établissements d'enseignement et de recherche français ou étrangers, des laboratoires publics ou privés. 


\begin{abstract}
FEEDBACK CONTROL OF THE SPRAY LIQUID DISTRIBUTION OF ELECTROSTATICALLY ASSISTED COAXIAL ATOMIZATION

Rodrigo Osuna-Orozco, ${ }^{1, *}$ Nathanael Machicoane, ${ }^{1}$ Peter D. Huck, ${ }^{1}$ E Alberto Aliseda ${ }^{1}$

${ }^{1}$ Department of Mechanical Engineering, University of Washington, Seattle, WA, 98105

*Address all correspondence to: Rodrigo Osuna-Orozco, Department of Mechanical Engineering, University of Washington, Seattle, WA, 98105 , E-mail: roo3@uw.edu Electrostatic actuation is used for real-time multiphysics feedback control of two-fluid coaxial atomization. This actuation is added to the modulation of the axial and angular momentum of the turbulent coaxial gas stream, for a total of three actuators to control atomization. We characterize the spray real-time response through optical scattering measurements of radial liquid distribution. We apply principal component analysis on the scattering radial profiles and correlate the first three principal components to the three control inputs. The control algorithm continuously adjusts the three inputs to minimize the difference between a goal radial profile representing the desired spray state and the profile observed in real time. This real-time multiphysics (gas momentum plus electrostatic repulsion) control on the liquid distribution in a two-fluid coaxial spray is a novel contribution to the archival literature on this technology.
\end{abstract}

KEY WORDS: real-time feedback control, two-fluid coaxial atomization, electrostatic atomization, multiphase flow, reduced order modeling, principal component analysis 


\section{INTRODUCTION}

2 Liquid atomization is ubiquitous in both the natural world and technological applications (e.g.

3 fuel injection, thin film coating, irrigation, manufacturing). Yet, in spite of its widespread use, the

4 development of real-time feedback control strategies for spray shaping remains a challenge, with

5 many open questions and opportunities for development in this area (Arai, 2019). In particular,

6 controlling the liquid volume fraction distribution in time and space is still an elusive objective.

7 This paper extends the authors' earlier work (Osuna-Orozco et al., 2019) on real-time feedback

8 control of coaxial atomization by adding an electrostatic actuation as well as expanding the range

9 of parameters over which the spray is controlled.

Both coaxial (Aliseda et al., 2008; Eggers and Villermaux, 2008; Lasheras et al., 1998; Marmottant and Villermaux, 2004) and electrostatic (Cloupeau and Prunet-Foch, 1994; Gañán-Calvo et al., 2018; Grace and Marijnissen, 1994; Kien Nguyen et al., 2014; Manna et al., 2017; RosellLlompart et al., 2018; Verdoold et al., 2014) atomizers have been the subject of intensive study in the last few decades. More recently, there has been increasing efforts to develop hybrid atomizers that include gas flow forcing as well as an electrostatic component (Fei et al., 2017; Kourmatzis et al., 2012; Li et al., 2014; Patel et al., 2017, 2016; Seong et al., 2017). These studies have revealed a wide range of atomization regimes that can be attainable with a rather simple atomizer geometry. Moreover, there has been an intense effort in developing control strategies for a variety of sprays, most notably, for fuel injection in combustion systems (Billoud et al., 1992; Coker et al., 2006; Conrad et al., 2007; Jones et al., 1999; McManus et al., 1993; Muruganandam et al., 2005; Murugappan et al., 2003).

Here, we present results for an electrostatically assisted two-fluid coaxial atomizer, where three control inputs shape the spray liquid distribution in real-time feedback. The sensing of the spray state is done through optical scattering, measuring a radial profile of liquid volume fraction at 18.5 gas diameters downstream of the nozzle. Applied voltage on the far field is actuated on, in addition to the actuation on the swirl and no-swirl gas flow rates. 

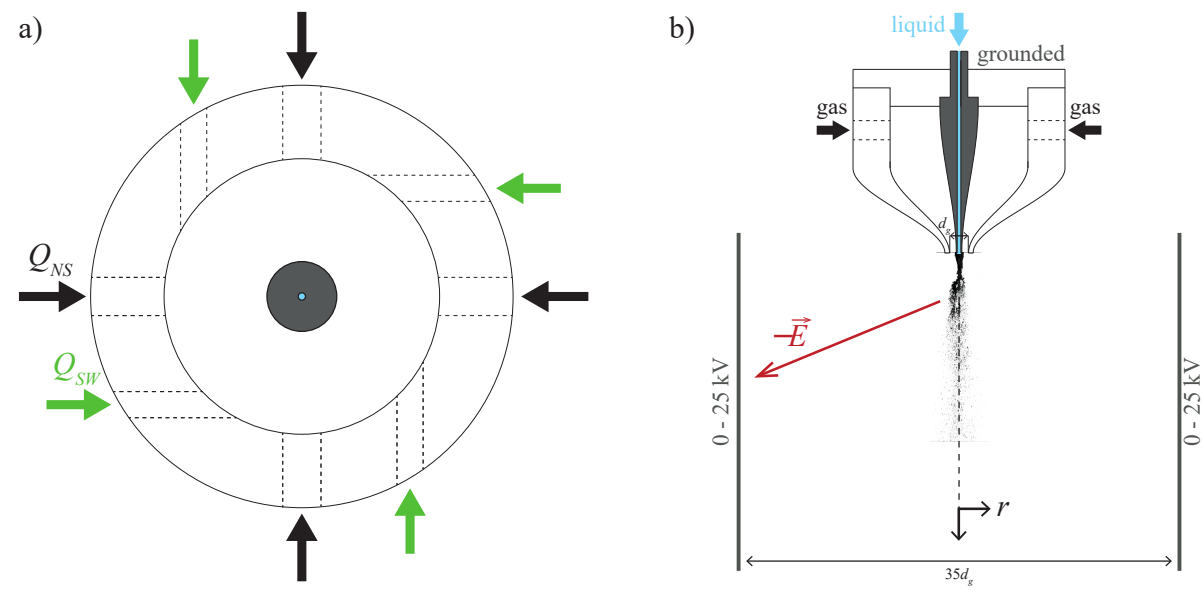

FIG. 1: (a) Plan view of the nozzle along the gas inlets plane showing the liquid channel in the middle and the eight inlets for gas. (b) Side view of the atomizer including the parallel plates (not to scale).

\section{2. EXPERIMENTAL SETUP}

\section{2.1 Atomizer and flow loop}

3 The two-fluid coaxial atomizer used in this work has been characterized extensively (Machicoane

4 et al., 2019; Osuna-Orozco et al., 2019). For the electrostatic actuation, the nozzle is placed be-

5 tween two parallel metallic plates and a voltage, variable between 0 and $25 \mathrm{kV}$, is equally applied

6 to both of them, while the nozzle remains grounded. The liquid flows through a straight needle

7 at the center of the gas nozzle at a constant flow rate, consistent with fully developed laminar

8 Poiseuille flow. The axial component of the gas flow is controlled by the gas flow rate from

9 four diametrically opposed, radially oriented, inlets perpendicular to the axis of the nozzle. The

10 angular component of the gas flow is controlled by the gas flow rate from four inlets that are 11 oriented tangential to the outer wall of the nozzle. The gas and liquid flow rates are controlled 12 independently with three proportional valves and a high voltage power supply controls the ap13 plied potential. A plan and side views of the nozzle, including the parallel plates, are shown in 14 figure 1 . The liquid nozzle internal and external diameters are respectively 2 and $3 \mathrm{~mm}$, while the gas nozzle internal diameter is $10 \mathrm{~mm}$.

16 This electrohydrodynamic multiphase flow can be characterized in terms of three dimen17 sionless groups: the gas-to-liquid momentum ratio $M=\rho_{g} U_{g}^{2} / \rho_{l} U_{l}^{2}$, the swirl ratio $S R=$ 
$1 Q_{n s} / Q_{s w}$, and the ratio of electric to surface tension energy, $\Gamma=\frac{\sigma_{0}^{2} / \epsilon_{0}}{\gamma / r_{0}}$, where the subscripts $2 g$ and $l$ denote the gas and liquid phases respectively, $\rho_{i}$ are the mass densities. The mean ve3 locities, $U_{i}$, are calculated from the volume flow rates $Q_{i}$, the subscripts $n s$ and $s w$ denote the 4 no-swirl and swirling components of the gas flow rate respectively, and $\gamma$ is the surface tension 5 between the liquid and gas phases. For the electrostatic variables, $\sigma_{0}$ is the surface charge den6 sity at the liquid-gas interface, $\epsilon_{0}$ is the permittivity of free space and $r_{0}$ the liquid needle radius.

7 Our working fluids were ambient air and water with a small concentration of sodium chloride 8 dissolved, with a conductivity of $2000 \mu \mathrm{S} / \mathrm{cm}$. For all the results presented, the liquid flow rate 9 was kept at $Q_{l}=99( \pm 2.5) \mathrm{ml} / \mathrm{min}$, corresponding to a liquid Reynolds number $R e_{l}=1200$. 10 The total gas flow rates explored in this study were in the range $150-860 S L P M$, resulting in velocities between 34 and $200 \mathrm{~m} / \mathrm{s}$ and momentum ratios between 5 and 175. For a given total

12 gas flow rate, the swirl ratio was varied in the range 0 to 1 . Charge densities up to $3 \mathrm{C} / \mathrm{m}^{3}$ were 13 observed.

\subsection{Light scattering measurements}

The control sensing consists of light scattering measurements along a radial profile through the spray. In contrast with the attenuation measurements used in our previous work, light scattering measurements allow for a more robust detection of spray features at lower volume fractions, which enables detection of lower mass loading reliably, at higher gas momentum ratio. A collimated light sheet is shined through the spray at an angle of 30 degrees with the horizontal plane, intersecting the spray between 18 and $19 d_{g}$ downstream from the nozzle (the gas inner diameter, $d g=1 \mathrm{~cm}$ and the plates are $35 d_{g}$ apart).

The light refracted by the spray droplets at $120^{\circ}$ forward scattering is collected by a linear CCD array camera (Thorlabs model LC100), forming a radial transverse profile, perpendicular to the spray axis and normal to the plane of the metallic plates. A Zeiss $100 \mathrm{~mm}$ macro lens was used for visualization, yielding a resolution of $77 \mu \mathrm{m}$, with a field of view of $16 \mathrm{~cm}$ wide. Figure 2 shows a schematic of the illumination mode used for measuring the radial profiles of the spray liquid distribution. As seen in the figure most of the spray width was captured in the collected 


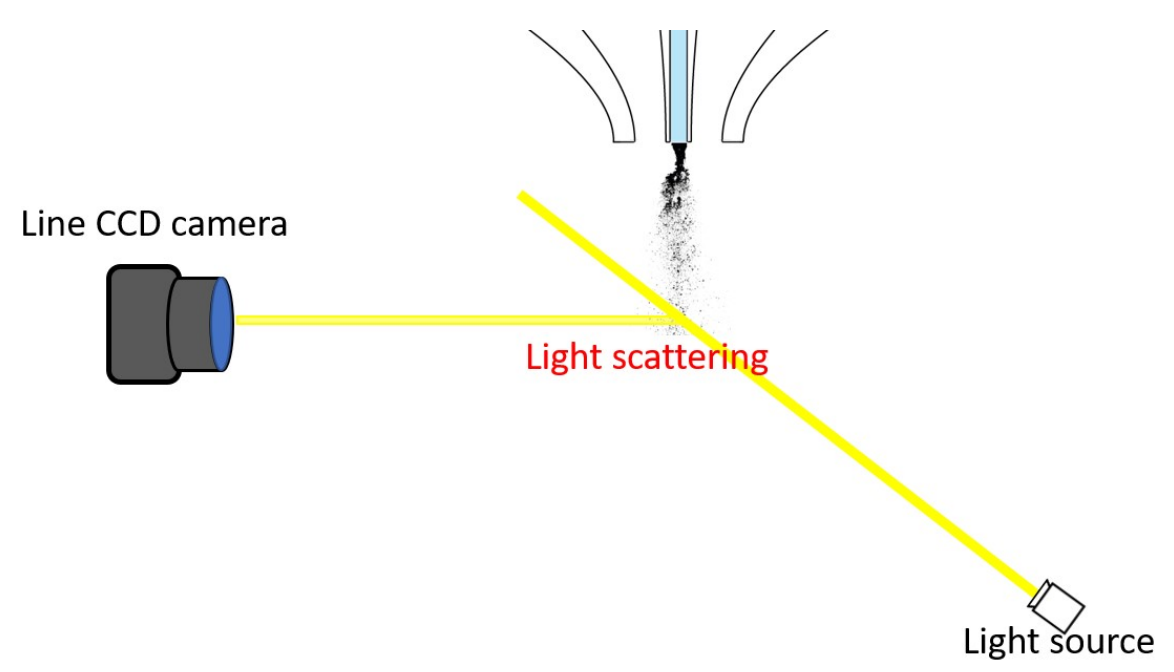

FIG. 2: Geometry of light scattering for spray visualization, showing the collimated plane of light that crosses the axis of the spray at an angle of 60 degrees.

1 images, with the scattered intensity at the edges approaching zero.

2 The optical scattering real-time sensing is able to capture the different features of the spray

3 over the range of control inputs studied. We explored momentum ratios from 5 to 175 , swirl

4 ratios from 0 to 1 and applied voltages of 0 to $25 \mathrm{kV}$ (corresponding to $\Gamma=0-1000$ ). Ap-

5 propriate filtering and sliding-time averaging reveal consistent profiles for varying actuation in

6 spite of the unsteadiness of the instantaneous liquid volume fraction signal, intrinsic to turbulent

7 flows. Figure 3 shows a small set of representative profiles that illustrate some of the features

8 of the spray at different values of the control inputs. As the momentum ratio increases, scatter-

9 ing increases because the droplet number-density increases, especially near the centerline of the

10 spray. Increasing the swirl ratio broadens the spray as droplets are transported away from the

11 spray centerline, but may result in a double bump feature in the scattered transverse profiles.

12 Finally, we observe a broadening of profiles as we increase the applied voltage, resulting both

13 from the electrostatic repulsion among charged spray droplets and by the electric field estab-

14 lished between the grounded nozzle and charged plates.

Volume x, Issue x, 2019 

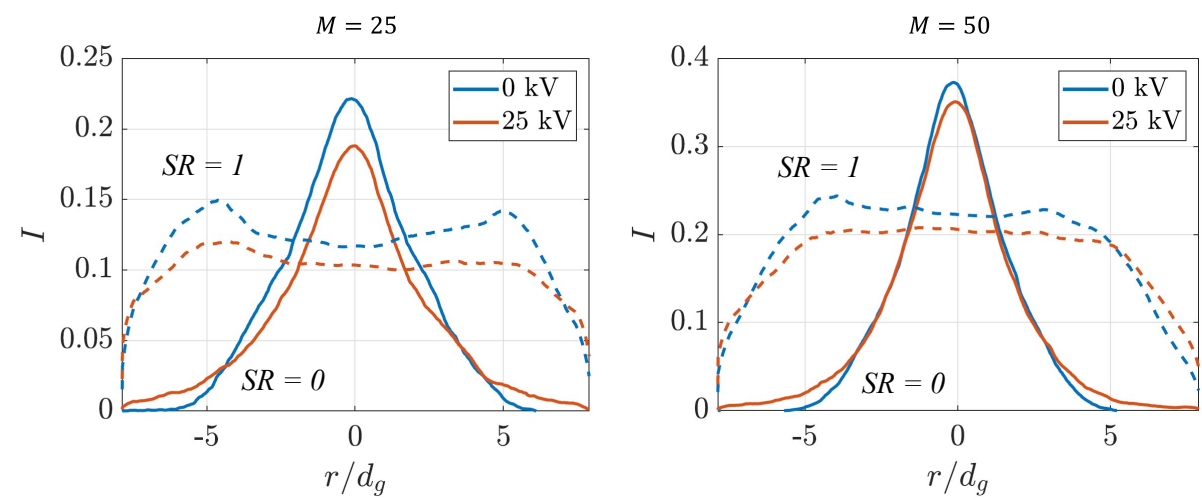

FIG. 3: Radial profiles of light scattering (representing liquid volume fraction) with (red) and without (blue) electrostatic actuation for swirl ratios of zero (solid lines) and swirl ratio of one (dashed lines) Left and right are respectively at a momentum ratio of 25 and 50.

\subsection{Principal Component Analysis of light scattering profiles}

2 Principal Component Analysis was performed onto a large data set collected over a wide range

3 of control inputs, in order to arrive at a reduced-order representation of the data. The dataset

4 included measurements for 140 different spray conditions with around 250 profiles for each

5 condition. The parameter space sampled was comprised of combinations of 7 momentum ratios

6 between 5 and 170, 5 swirl ratios between 0 and 1 and 4 voltages between 0 and $25 \mathrm{kV}$. We

7 used a standard implementation of PCA using MATLAB's Singular Value Decomposition built-

8 in functions and standard algorithms as the ones detailed by Kutz. (Kutz, 2013). Most of the

9 features of the collected profiles could be adequately and sparsely represented by the main three

10 principal components which contained about $84 \%$ of the energy. As shown in Figure 4 accurate

11 reconstructions were achieved with the first three principal components.

12 More importantly, the distance between the two profiles as measured by the integral over the profile of the normalized root-mean-squared difference and by the sum of the normalized rootmean-squared difference of their three principal components closely match each other (Figure $4 b)$ ). This property guarantees that two profiles that are close in the principal component parameter space will indeed be very similar in physical space, such that convergence of the principal component coefficients ensures that the desired profile goal will be achieved.

The resulting reduced-order representations were correlated to the control inputs using a 

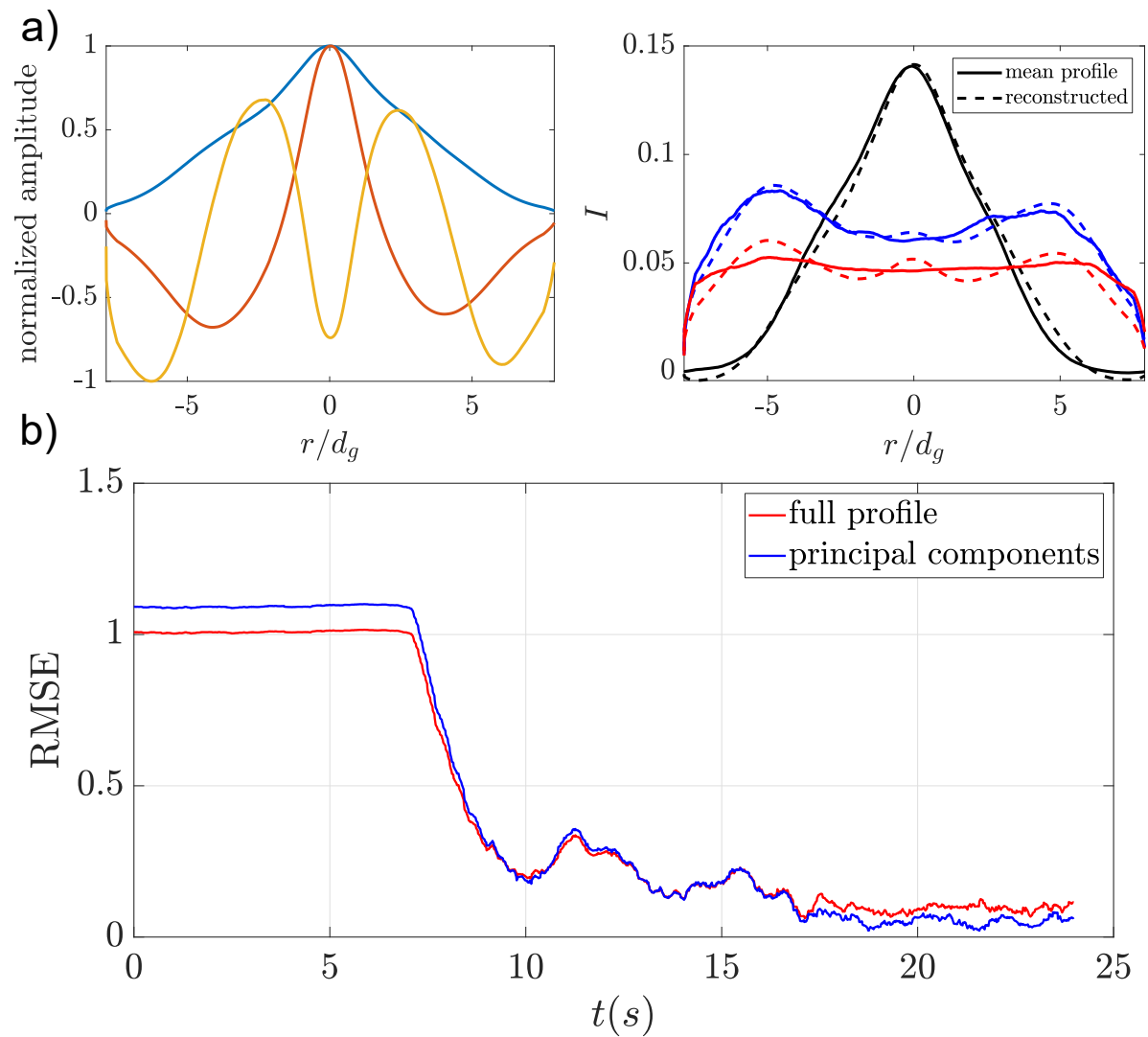

FIG. 4: (a) First Three Principal Components normalized by their maxima (Left). Measured profiles (solid lines) and principal component reconstructions (dashed lines) (Right). (b) Normalized root mean square error time series between the goal and the real-time measurement computed from the full data (solid) and the PCA decomposition (dashed).

1 least squares linear fit, in a 3 by 3 matrix, in order to obtain a linear map between the observed

2 profiles and the control variables.

\section{REAL-TIME FEEDBACK CONTROL IMPLEMENTATION}

\section{$4 \quad 3.1$ Control Performance}

5 The goal of the spray control is to drive the experimental spray towards a desired state, charac-

6 terized by a liquid volume profile measured with the light scattering on the line CCD camera.

7 The control inputs are adjusted in real-time by the closed-loop control algorithm, based on a lin-

8 ear mapping obtained from the open loop investigation with a gain that is adjusted based on the

Volume x, Issue x, 2019 

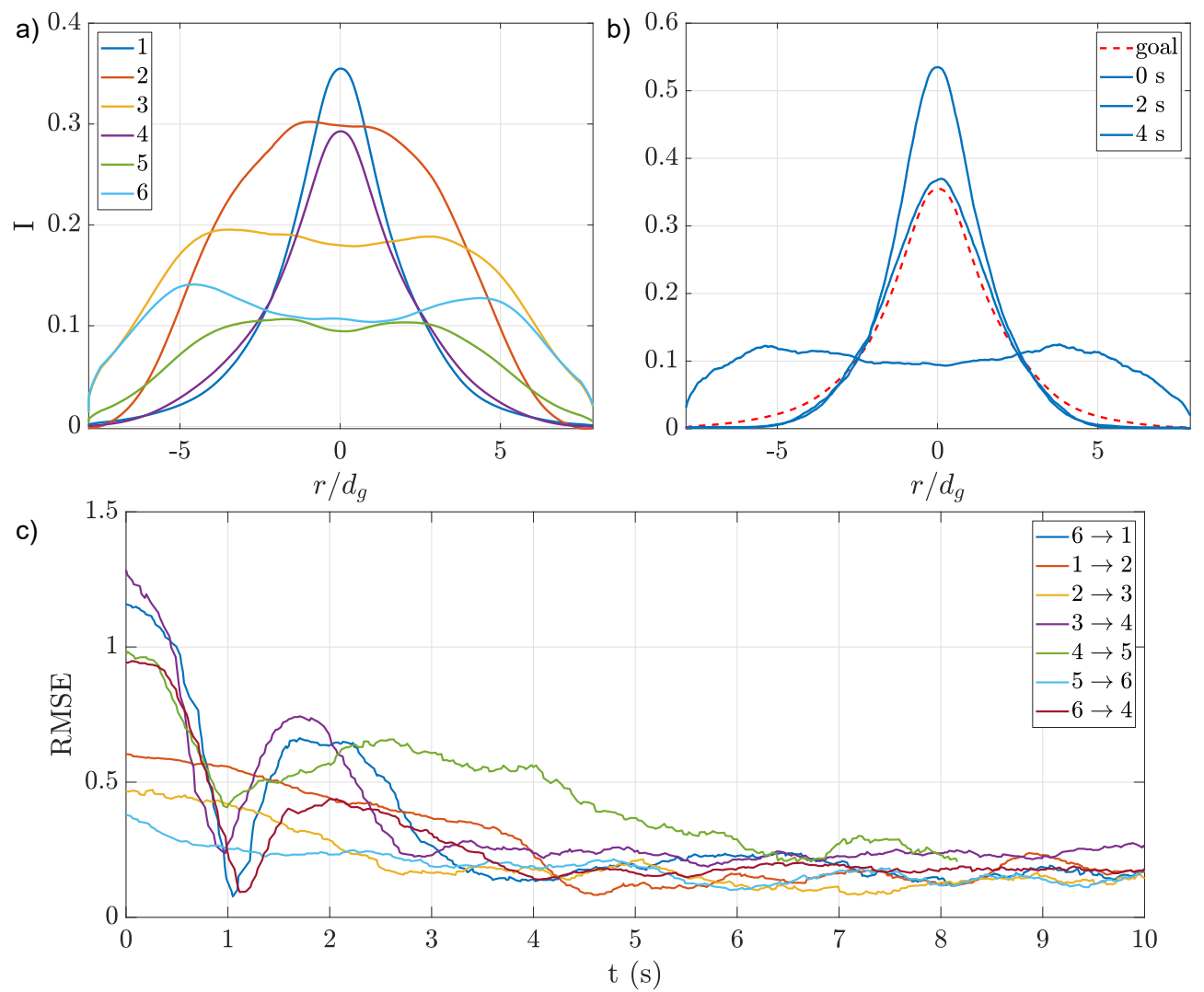

FIG. 5: (a) Goal profiles used to test the control algorithm as shown in the supplementary video. (b) Example of control algorithm convergence, progressing from profile 6 to 1. (c) Normalized root mean square errors between real-time profiles and goals (desired light profiles in the spray). The legend indicates the starting profile as numbered in the supplementary video and the goal profile.

1 real-time error. This results in an closed-loop iterative approach (with a frequency of iteration

2 being approximately $100 \mathrm{~Hz}$ ) with control input adjustments that decrease as the desired pro-

3 file is approached (Osuna-Orozco et al., 2019). The algorithmic gains are set as a compromise

4 between convergence speed and stability/robustness to process noise.

$5 \quad$ As seen in figure 5 (and in the movie included in the supplementary material), our control

6 algorithm leads to convergence upon a wide variety of specified goals. Table 1 below presents

7 the mean convergence error, $\langle\varepsilon\rangle$, and the standard deviation of the convergence error, $\varepsilon^{\prime}$, for

8 the control examples in the supplementary video and in figure 5. The standard deviation of the

9 normalized convergence error is a fraction of the convergence error. The signal shows greater

10 variance at higher values of the swirl ratio, which is also apparent in higher variance of the 
convergence error for such cases.

TABLE 1: Closed loop control performance metrics.

\begin{tabular}{|cccccc|}
\hline $\mathrm{M}$ & $\mathrm{SR}$ & Voltage $(\mathrm{kV})$ & $\langle\varepsilon\rangle$ & $\varepsilon^{\prime}$ & $100 \cdot \frac{\varepsilon^{\prime}}{\langle\varepsilon\rangle}$ \\
\hline \hline 59 & 0.21 & 0.0 & 0.10 & 0.01 & 8.94 \\
\hline 87 & 0.40 & 20.7 & 0.05 & 0.01 & 26.44 \\
\hline 48 & 0.70 & 8.9 & 0.10 & 0.03 & 25.89 \\
\hline 49 & 0.24 & 0.0 & 0.09 & 0.01 & 9.22 \\
\hline 27 & 0.38 & 6.2 & 0.21 & 0.03 & 16.29 \\
\hline 22 & 0.56 & 8.8 & 0.05 & 0.01 & 28.35 \\
\hline
\end{tabular}

\section{CONCLUSIONS}

3 We demonstrate multi-physics control, using an external electric field to both charge the spray

4 droplets and attract the charged droplets radially outwards as they flow downstream of the noz-

5 zle. This extends previous work on real-time feedback control of the spray liquid distribution in

6 two significant ways: 1) adopting a more robust sensing technique that captures features of the

7 spray more accurately, even in less dense sprays, over a broader range of momentum ratios and

8 swirl ratios; 2) and by adding an electrostatic actuation. To the best of the authors' knowledge,

9 this is the first instance of real-time feedback control on the liquid distribution of a two-fluid

10 coaxial spray using multiphysics actuation. Future work will explore more robust control al-

11 gorithms, additional multi-physics actuations and will establish more closely the link between

12 the scattering measurements and the physical variables that characterize the spray (e.g. volume

13 fraction, area fraction, mass flux).

\section{ACKNOWLEDGMENTS}

This work was sponsored by the Office of Naval Research (ONR) as part of the Multidisciplinary University Research Initiatives (MURI) Program, under grant number N00014-16-1-2617. The views and conclusions contained herein are those of the authors only and should not be interpreted as representing those of ONR, the U.S. Navy or the U.S. Government.

Volume x, Issue x, 2019 


\section{REFERENCES}

Aliseda, A., Hopfinger, E., Lasheras, J., Kremer, D., Berchielli, A., and Connolly, E., Atomization of viscous and non-newtonian liquids by a coaxial, high-speed gas jet. Experiments and droplet size modeling, International Journal of Multiphase Flow, vol. 34, no. 2, pp. 161-175, 2008.

Arai, M., The Possibility of Active Attitude Control for Fuel Spray, Engineering, vol. 5, no. 3, pp. 519-534, 2019.

Billoud, G., Galland, M.A., Huu, C.H., and Candel, S., Adaptive Active Control of Combustion Instabilities, Combustion Science and Technology, vol. 81, no. 4-6, pp. 257-283, 1992.

Cloupeau, M. and Prunet-Foch, B., Electrohydrodynamic spraying functioning modes: a critical review, Journal of Aerosol Science, vol. 25, no. 6, pp. 1021-1036, 1994.

Coker, A., Neumeier, Y., Zinn, B.T., Menon, S., and Lieuwen, T., Active instability control effectiveness in a liquid fueled combustor, Combustion Science and Technology, vol. 178, no. 7, pp. 1251-1261, 2006.

Conrad, T., Bibik, A., Shcherbik, D., Lubarsky, E., and Zinn, B., Feasibility of "intermittent” active control of combustion instabilities in liquid fueled combustors using a "smart" fuel injector, Proceedings of the Combustion Institute, vol. 31, no. 2, pp. 2223-2230, 2007.

Eggers, J. and Villermaux, E., Physics of liquid jets, Reports on Progress in Physics, vol. 71, no. 3, 2008.

Fei, L., Yoo, S.H., Villamayor, R.A.R., Williams, B.P., Gong, S.Y., Park, S., Shin, K., and Joo, Y.L., Graphene Oxide Involved Air-Controlled Electrospray for Uniform, Fast, Instantly Dry, and Binder-Free Electrode Fabrication, ACS Applied Materials \& Interfaces, vol. 9, no. 11, pp. 9738-9746, 2017.

Gañán-Calvo, A.M., López-Herrera, J.M., Herrada, M.A., Ramos, A., and Montanero, J.M., Review on the physics of electrospray: From electrokinetics to the operating conditions of single and coaxial Taylor cone-jets, and AC electrospray, Journal of Aerosol Science, vol. 125, pp. 32-56, 2018.

Grace, J. and Marijnissen, J., A review of liquid atomization by electrical means, Journal of Aerosol Science, vol. 25, no. 6, pp. 1005-1019, 1994.

Jones, C.M., Lee, J.G., and Santavicca, D.A., Closed-loop active control of combustion instabilities using subharmonic secondary fuel injection, Journal of Propulsion and Power, vol. 15, no. 4, pp. 584-590, 1999.

Kien Nguyen, T., Nguyen, V.D., Seong, B., Hoang, N., Park, J., and Byun, D., Control and improvement of jet stability by monitoring liquid meniscus in electrospray and electrohydrodynamic jet, Journal of 
Aerosol Science, vol. 71, pp. 29-39, 2014.

Kourmatzis, A., Ergene, E.L., Shrimpton, J.S., Kyritsis, D.C., Mashayek, F., and Huo, M., Combined aerodynamic and electrostatic atomization of dielectric liquid jets, Experiments in Fluids, vol. 53, no. 1, pp. 221-235, 2012.

Kutz, J.N., Data-Driven Modeling \& Scientific Computation : Methods for Complex Systems \& Big Data, first edition. Edition, Oxford University Press, Oxford, 2013.

Lasheras, J.C., Villermaux, E., and Hopfinger, E.J., Break-up and atomization of a round water jet by a high-speed annular air jet, Journal of Fluid Mechanics, vol. 357, pp. 351-379, 1998.

Li, G., Luo, X., Si, T., and Xu, R.X., Temporal instability of coflowing liquid-gas jets under an electric field, Physics of Fluids, vol. 26, no. 5, p. 054101, 2014.

Machicoane, N., Bothell, J.K., Li, D., Morgan, T.B., Heindel, T.J., Kastengren, A.L., and Aliseda, A., Synchrotron radiography characterization of the liquid core dynamics in a canonical two-fluid coaxial atomizer, International Journal of Multiphase Flow, vol. 115, pp. 1-8, 2019.

Manna, L., Carotenuto, C., Nigro, R., Lancia, A., and Di Natale, F., Primary atomization of electrified water sprays, The Canadian Journal of Chemical Engineering, vol. 95, no. 9, pp. 1781-1788, 2017.

Marmottant, P. and Villermaux, E., On spray formation, Journal of Fluid Mechanics, vol. 498, pp. 73-111, 2004.

McManus, K., Poinsot, T., and Candel, S., A review of active control of combustion instabilities, Progress in Energy and Combustion Science, vol. 19, no. 1, pp. 1-29, 1993.

Muruganandam, T.M., Nair, S., Scarborough, D., Neumeier, Y., Jagoda, J., Lieuwen, T., Seitzman, J., and Zinn, B., Active control of lean blowout for turbine engine combustors, Journal of Propulsion and Power, vol. 21, no. 5, pp. 807-814, 2005.

Murugappan, S., Acharya, S., Allgood, D.C., Park, S., Annaswamy, A.M., and Ghoniem, A.F., Optimal control of a swirl-stabilized spray combustor using system identification approach, Combustion Science and Technology, vol. 175, no. 1, pp. 55-81, 2003.

Osuna-Orozco, R., Machicoane, N., Huck, P.D., and Aliseda, A., FEEDBACK CONTROL OF COAXIAL ATOMIZATION BASED ON THE SPRAY LIQUID DISTRIBUTION, Atomization and Sprays, vol. 29, no. 6 , pp. 545-551, 2019.

Patel, M.K., Praveen, B., Sahoo, H.K., Patel, B., Kumar, A., Singh, M., Nayak, M.K., and Rajan, P., An

Volume x, Issue x, 2019 
1 advance air-induced air-assisted electrostatic nozzle with enhanced performance, Computers and Elec-

2 tronics in Agriculture, vol. 135, pp. 280-288, 2017.

3 Patel, M.K., Sahoo, H.K., Nayak, M.K., and Ghanshyam, C., Plausibility of variable coverage high range

4 spraying: Experimental studies of an externally air-assisted electrostatic nozzle, Computers and Elec-

$5 \quad$ tronics in Agriculture, vol. 127, pp. 641-651, 2016.

6 Rosell-Llompart, J., Grifoll, J., and Loscertales, I.G., Electrosprays in the cone-jet mode: From Taylor cone

7 formation to spray development, Journal of Aerosol Science, vol. 125, no. May, pp. 2-31, 2018.

8 Seong, B., Hwang, S., Jang, H.S., Lee, H., Kim, J., Nguyen, V.D., Cho, D.H., Lin, L., and Byun, D., A

9 hybrid aerodynamic and electrostatic atomization system for enhanced uniformity of thin film, Journal 10 of Electrostatics, vol. 87, pp. 93-101, 2017.

11 Verdoold, S., Agostinho, L., Yurteri, C., and Marijnissen, J., A generic electrospray classification, Journal of Aerosol Science, vol. 67, pp. 87-103, 2014. 